\title{
PENGARUH GEMPA TERHADAP PERILAKU JEMBATAN CABLE STAYED TENGKU FISABILILAH RIAU DENGAN TIME HISTORY ANALYSIS
}

\author{
Natalia Vin Kristin ${ }^{1}$, Ari Wibowo ${ }^{2}$, Desy Setyowulan², Edhi Wahyuni S. ${ }^{2}$ \\ ${ }^{1}$ Mahasiswa / Program Studi Sarjana Teknik Sipil Fakultas Teknik / Universitas Brawijaya \\ ${ }^{2}$ Dosen / Jurusan Teknik Sipil Fakultas Teknik / Universitas Brawijaya \\ Korespondensi: nataliavinkristin@yahoo.com
}

\begin{abstract}
Tengku Fisabilillah Riau Bridge is one type of a cable stayed bridge that located in Indonesia. Indonesia is among one of the countries that are prone to earthquakes. Effects of earthquake can change the structure of the bridge. These effects can be analyzed using time history analysis.The first step begins with the modeling of bridge structures. But the dimensions and material specifications of the bridge's structure has been determined by researcher. After modeling the structure of the bridge is completed, input the data of the time history. This data is taken from the earthquake of Hyogo-Ken Nanbu in Japan. Next, the changes of the structure of the bridge caused by the earthquake such as mode shapes, displacement, and stress that occur will be analyzed. Results of the analysis showed that there were many mode shapes generated, the largest mode shapes is on the $Y$-axis at the direction of the bridge. For displacement, the maximum displacement occurs direction in Z-axis. The deflection that caused by the earthquake is largest than the allowable maximum deflection of the bridge. While, the maximum stress occurs on the cable. The force which is caused by the earthquake is largest than the allowable maximum force owned section.
\end{abstract}

Keywords: bridge, cable stayed bridge, mode shapes, displacement, stress, time history analysis

\section{PENDAHULUAN}

Jembatan merupakan suatu struktur yang berfungsi sebagai penghubung dua bagian jalan yang terputus akibat adanya sungai, danau, lembah, maupun laut. Jembatan Tengku Fisabililah Riau adalah salah satu jembatan cable stayed terbesar di Indonesia.

Indonesia merupakan negara yang rentan mengalami gempa bumi. Terjadinya gempa bumi dapat memberikan pengaruh terhadap struktur jembatan yang sudah dibangun. Perubahan perilaku terhadap struktur pun dapat dianalisis sesuai pengaruh yang diakibatkan oleh gempa itu sendiri. Untuk menganalisis beban gempa pada suatu struktur dapat dilakukan dengan 2 metode yaitu metode analisis riwayat waktu dan metode respon spectrum, dimana metode tersebut populer digunakan oleh para analis/desain struktur [4][5][6].

Time history analysis atau analisis riwayat waktu merupakan analisis dinamis yang dapat dilakukan dengan memperhatikan pergerakan tanah di sekitar lokasi struktur. Hasil analisis ini berupa beban gempa untuk setiap waktu selama durasi gempa, sehingga diperoleh nilai percepatan gempa itu sendiri.

Maksud dan tujuan dari analisis ini adalah untuk mengetahui mode shapes, besar displacement, dan besar tegangan yang terjadi pada jembatan cable stayed saat dimasukkan data time history.

\section{TINJAUAN PUSTAKA}

\subsection{Jembatan Cable Stayed}

Jembatan cable stayed merupakan salah satu jenis jembatan dimana struktur utama yang bekerja pada jembatan adalah kabel. Adapun komponen utama jembatan cable stayed adalah gelagar, menara/pylon dan sistem kabel.

1. Gelagar

Terdapat dua jenis gelagar yang paling banyak digunakan, yaitu stiffening truss dan solid web. Stiffening truss digunakan untuk struktur baja, sedangkan solid web 
digunakan unuk struktur baja atau beton bertulang maupun beton prategang.

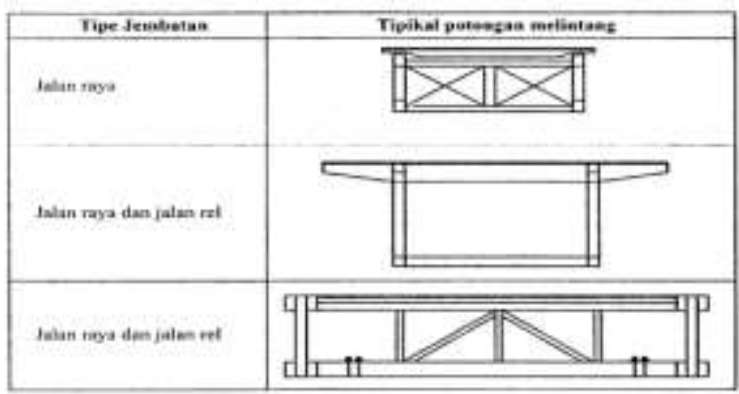

Gambar 1. Gelagar stiffening truss

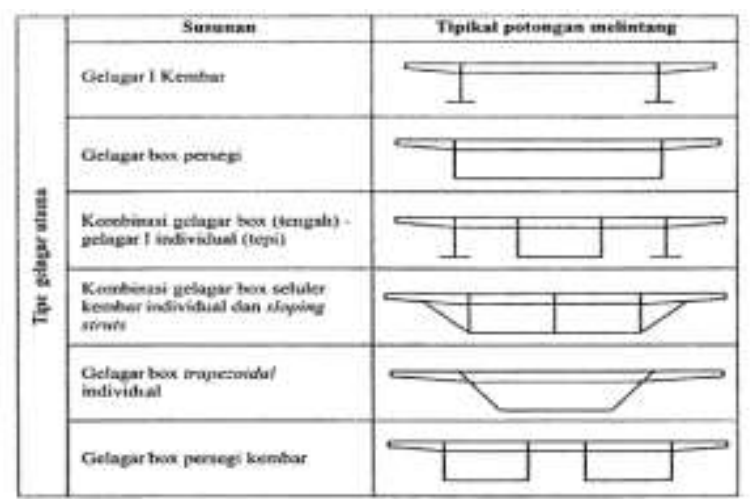

Gambar 2. Gelagar solid web

2. Menara/pylon

Pemilihan bentuk menara dipengarui oleh beberapa faktor seperti estetika, kebutuhan, konfigurasi kabel, maupun biaya yang akan dikeluarkan. Bentuk-bentuk menara antara lain portal trapezoidal, menara kembar, menara A, dan menara tunggal .

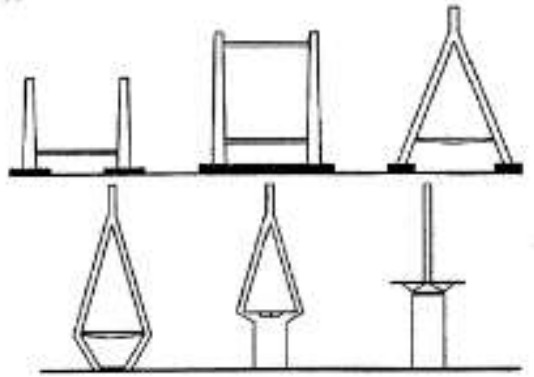

Gambar 3. Bentuk pylon

3. Sistem Kabel

Secara umum sistem kabel dapat dilihat sebagai tatanan kabel transversal dan tatanan kabel longitudinal. Tatanan kabel transversal dibagi menjadi dua yaitu, sistem satu bidang dan sistem dua bidang. Sedangkan tatanan kabel longitudinal dibedakan menjadi tipe radiating, tipe harp, tipe fan, dan tipe star.

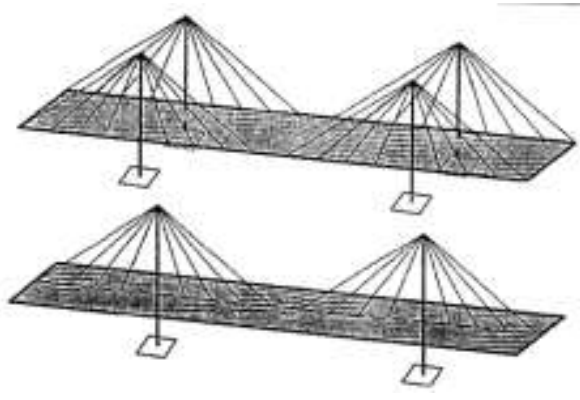

Gambar 4. Tatanan kabel transversal, dua bidang dan satu bidang
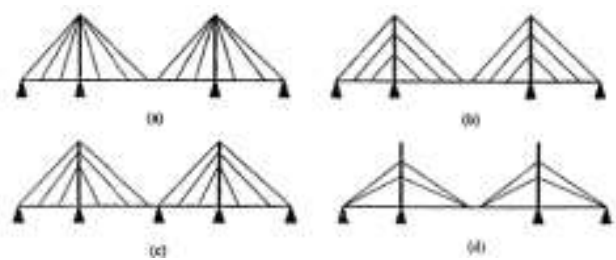

Gambar 5. Tatanan kabel longitudinal (a) radiating, (b) harp, (c) fan, (d) star

\subsection{Efek Non-Linier pada Elemen Struktur}

Struktur jembatan cable stayed merupakan struktur yang mempunyai efek non-linier yang cukup berpengaruh [2]. Meskipun struktur memiliki efek non-linier, hal ini dapat diabaikan dengan memberikan anggapan-anggapan tertentu. Tiga penyebab sifat non-linier adalah sag pada kabel, efek P-delta, dan sifat material.

\subsection{Gempa Bumi}

Gempa bumi adalah getaran atau guncangan yang terjadi di permukaan bumi, akibat adanya benturan pergesekan pada kerak bumi. Getaran ini berupa gelombang yang mempunyai energi untuk menggetarkan bangunan diatasnya. Berdasarkan penyebabnya gempa bumi dibedakan menjadi, gempa bumi tektonik, gempa bumi vulkanik, gempa bumi runtuhan, dan gempa bumi buatan.

\subsection{Analisis Dinamis}

Analisis dinamis merupakan suatu metode analisis struktur dengan getaran gempa yang dimodelkan sebagai beban dinamis, yaitu beban yang arah dan besarnya berubah setiap waktu . Salah satu analisis dinamis yang biasa dilakukan adalah time history analysis (analisis riwayat waktu). Time history analysis sangat cocok digunakan untuk menganalisis struktur yang tidak beraturan terhadap pengaruh gempa 
rencana [3]. Pada analisis ini struktur yang di desain diberi percepatan pada permukaan tanah sesuai rekaman percepatan terhadap waktu dari data time history.

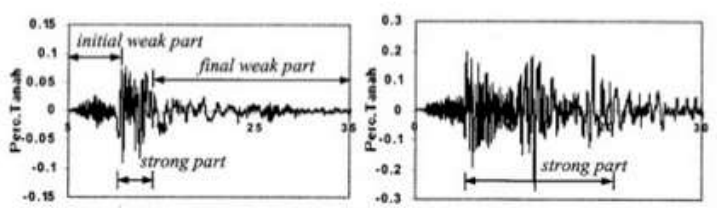

Gambar 6. Rekaman gempa Taiwan 1999

\section{METODE PENELITIAN}

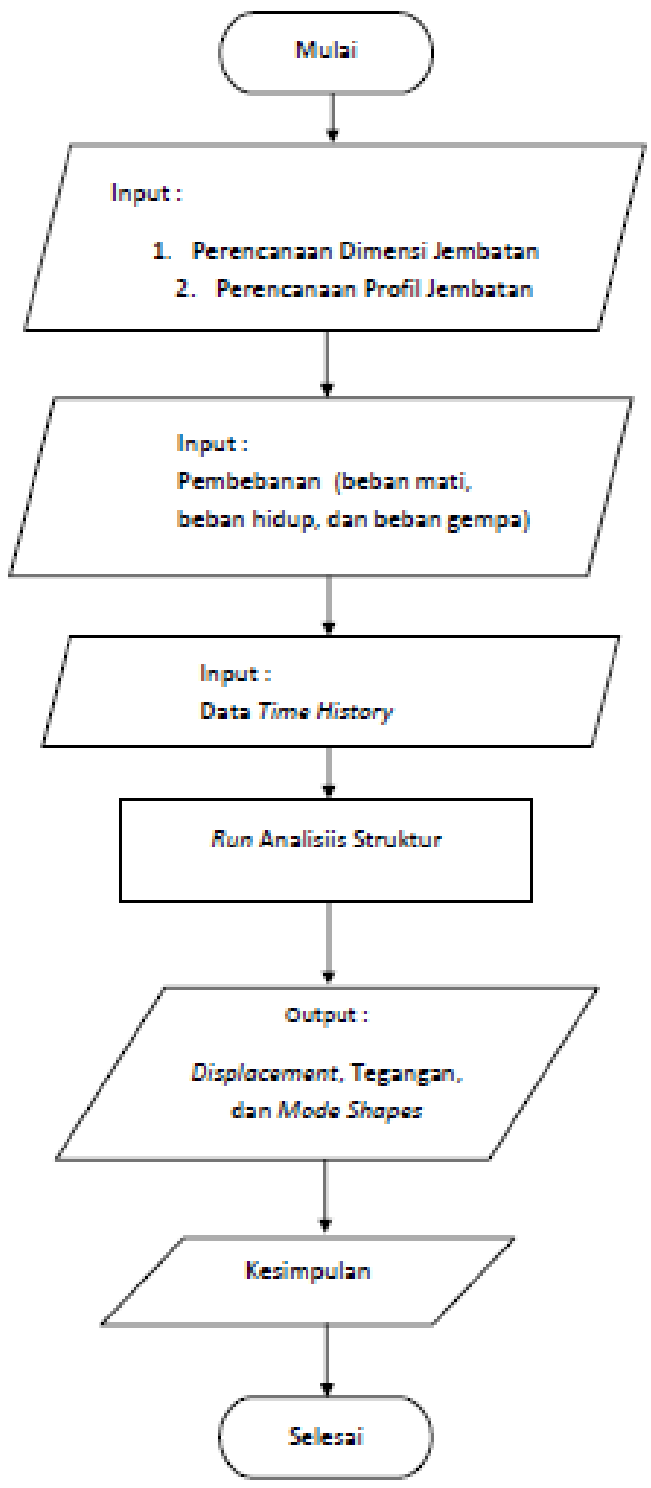

Gambar 7. Diagram alir penelitian

\subsection{Preliminary Design}

Dalam analisis ini, objek kajian menggunakan Jembatan Tengku Fisabililah yang berada di Keplauan Riau. Jembatan ini biasa dikenal dengan Jembatan Balerang 1 yang merupakan jenis jembatan cable stayed. Total panajng jembatan adalah 642 meter, dimana jembatan berfungsi sebagai jalan raya.

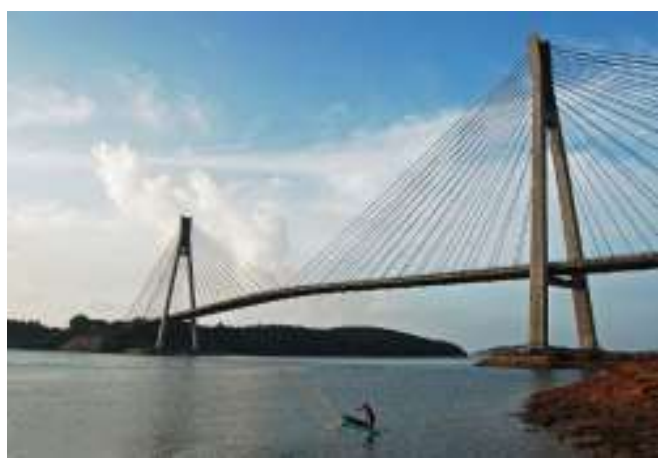

Gambar 8. Jembatan Tengku Fisabililah

\subsection{Pemodelan Struktur Jembatan}

Perencanaan struktur jembatan didesain mengikuti model dua dimensi struktur Jembatan Tengku Fisabillilah di Riau namun dengan spesifikasi material dan dimensi yang dimodifikasi peneliti. Proses perencanaan dilakukan dengan menggunakan program AutoCAD 2013 dan SAP2000 v.18. Selain itu juga dimasukan pembebanan yang terjadi berdasarkan SNI-1725-2016 tentang Pembebanan untuk Jembatan [1].

\subsection{Input Data Time History}

Memasukan data time history pada program SAP2000 v.18 sebagai penetapan fungsi struktur pada program. Sesudah itu menetapkan time history sebagai beban gempa yang terjadi dan menentukan skala faktor, banyaknya data percepatan, interval waktu pergerakan, dan faktor dumping yang digunakan. Terakhir menjalankan analisis dengan run analyze.

\section{HASIL DAN PEMBAHASAN}

4.1 Pemodelan Struktur Jembatan Tengku Fisabililah

Total panjang jembatan adalah 642 meter yang terdiri dari 2 bentang tepi masing-masing sepanjang 146 meter dan bentang utama sepanjang 350 meter. Terdapat 2 buah pylon pada jembatan dengan tinggi 90 meter dari gelagar dan 28 meter dari muka air. Jembatan ini mempunyai lebar sebesar 21,5 meter dengan 2 jalur dimana setiap jalur terdapat 2 lajur, serta trotoar selebar 1 meter yang terletak disisi kanan dan kiri jembatan. Secara umum jembatan ini terbuat dari bahan beton. 


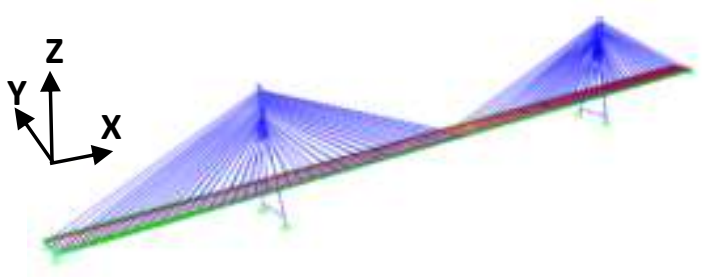

Gambar 9. Layout Jembatan Tengku Fisabililah tampak 3D

- Gelagar Jembatan

Mutu beton yang digunakan pada gelagar induk maupun gelagar melintang adalah K-500 dengan bentuk penampang kotak. Terdapat 2 buah gelagar induk pada jembatan yang berjarak 21,5 meter secara memanjang dengan dimensi 3,6 m x $2 \mathrm{~m}$. Sedangkan terdapat 215 buah gelagar melintang berdimensi $1,8 \mathrm{~m} \times 0,9 \mathrm{~m}$ yang dipasang setiap 3 meter. Selain itu terdapat pula pelat beton setebal $25 \mathrm{~cm}$.

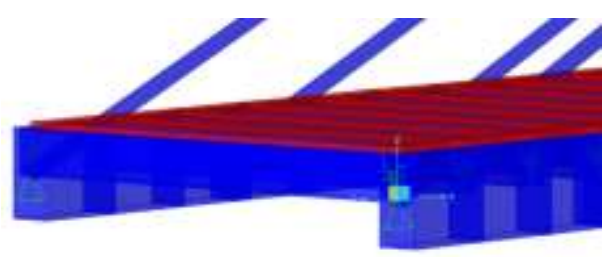

Gambar 10. Gelagar jembatan 3D

- Pylon

Terdapat 2 buah pylon pada jembatan dengan dimensi $7 \mathrm{~m}$ x 5,5 m yang bermutu K-600. Serta balok pada pylon dengan dimensi $3 \mathrm{~m}$ x 2,5 m sebanyak 2 buah. Total tinggi pylon dari muka air 118 meter. Bentuk dari pylon merupakan perpaduan antara menara A dengan menara kembar.

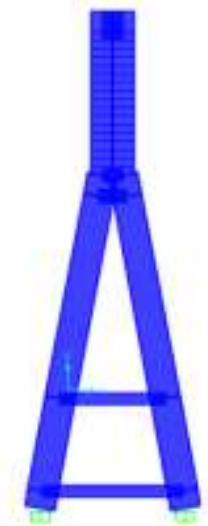

Gambar 11. Pylon 3D

- Sistem Kabel

Sistem kabel yang digunakan adalah sistem kabel dua bidang dimana kabel menarik gelagar induk dikedua bidang kanan dan kiri jembatan. Pada satu bidang, terdapat 16 buah kabel pada masing-masing bentang tepi dan 34 buah kabel pada bentang utama. Penempatan kabel ini berjarak setiap 8,588 meter pada bentang tepi dan setiap 10 meter pada bentang utama dengan tipe kabel harp. Untuk spesifikasi kabel diambil dari kabel yang di produksi oleh Tensacciai yang merupakan perusahaan yang memproduksi kabel untuk jembatan cable stayed. Kabel terbuat dari baja yang terdiri dari 169 strands dengan total diameter $20,4 \mathrm{~cm}, f y=1860 \mathrm{MPa}$, $f u=2010 \mathrm{MPa}$ dan modulus elastisitas $(E)=$ 2,05 x $105 \mathrm{MPa}$.

\subsection{Pembebanan dan Kombinasi Pembebanan Jembatan}

Pada analisis dimasukkan beban mati (selfweight), beban mati tambahan, dan beban gempa. Beban mati (MS) berupa berat sendiri dari gelagar induk, gelagar melintang, pylon dan pelat. Beban mati tambahan (MA) berupa beban trotoar setebal $25 \mathrm{~cm}$ dan beban aspal setebal 10 $\mathrm{cm}$. Serta beban gempa (EQ) berupa rekaman pergerakan percepatan tanah. Berdasarkan SNI 1725 Tahun 2016 didapatkan kombinasi beban mati ditambah beban gempa adalah 1,3 MS + 2 MA + EQ. Sedangkan untuk menghitung besarnya displacement digunakan kombinasi beban mati ditambah beban gempa adalah $1 \mathrm{MS}$ $+1 \mathrm{MA}+1 \mathrm{EQ}$.

\subsection{Time History Analysis Gempa Hyogo- Ken Nanbu}

Pemilihan gempa Hyogo-Ken Nanbu selain gempa yang berasal dari Jepang dimana karakteristik geografinya menyerupai Indonesia, namun juga didasari oleh ketersediaan data yang dimiliki peneliti. Gempa bumi Hyogo-Ken Nanbu terjadi pada tanggal 17 Januari 1995 pukul 5:46 pagi waktu setempat. Berpusat pada $20 \mathrm{~km}$ arah baratdaya dari pusat kota Kobe. Besar gempa bumi mencapai 7,2 skala ricter dengan kedalaman $10 \mathrm{~km}$ dibawah permukaan laut.

Rekaman pergerakan gempa yang diperoleh peneliti berasal dari stasiun gempa Kobekaiyokishodai di Jepang yang terdiri dari percepatan tanah arah utara-selatan (Y) dan arah barat-timur $(\mathrm{X})$. Berdasarkan data diketahui gempa terjadi selama 30 detik dengan interval waktu 0,01 detik. Data rekaman ini dimasukan sebagai beban gempa arah $\mathrm{x}$ dan $\mathrm{y}$ secara bersamaan. Percepatan tanah ditaksir sebesar 500 sampai $800 \mathrm{~cm} / \mathrm{s} 2$ dan modal damping 
dipakai sebesar $2 \%$. Pemasukan data rekaman ini dilakukan menggunakan program SAP2000 v.18.

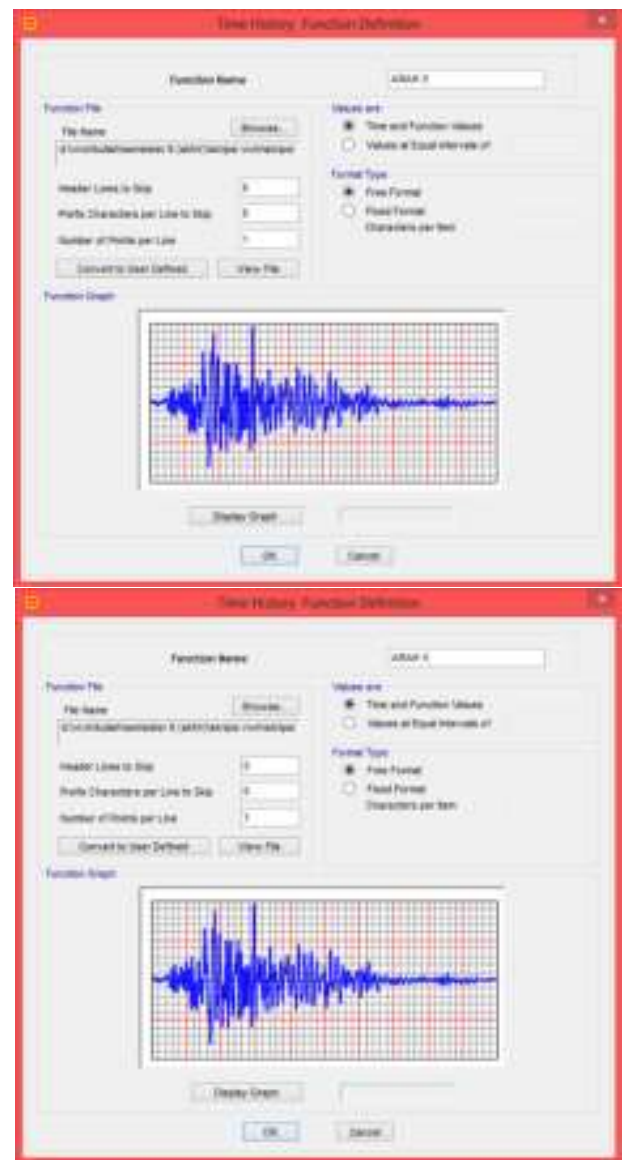

Gambar 12. Proses input rekaman gempa Hyogo-Ken Nanbu sebagai time history function

\subsection{Mode Shape yang Dihasilkan Jembatan}

Pada analisis digunakan keadaan arah gempa utara-selatan merupakan arah jembatan sumbu $X$ dan arah gempa barat-timur merupakan arah jembatan sumbu Y. SAP2000 v.18 menampilkan 12 macam mode shapes yang terjadi pada struktur jembatan. Setiap mode terdapat frekuensi natural yang berbeda dengan mode lainnya. Hal ini yang mempengaruhi tiap mode mempunyai perbedaan bentuk. Berdasarkan modal participating mass ratio, mode 1 adalah mode terbesar arah sumbu $\mathrm{Y}$ sebesar 0,332 satuan perpindahan, mode 9 adalah mode terbesar arah sumbu $\mathrm{X}$ sebesar 0,095 satuan perpindahan, dan mode 12 adalah mode terbesar arah sumbu $\mathrm{Z}$ sebesar 0,242 satuan perpindahan.

Gambar 13. Mode $1, \mathrm{~T}=4,9351$ detik

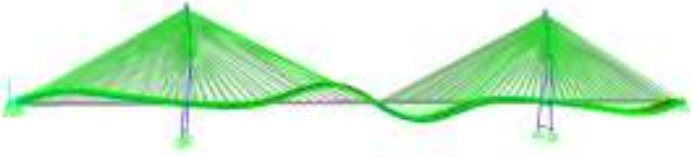

Gambar 14. Mode $9, \mathrm{~T}=0.9297$ detik

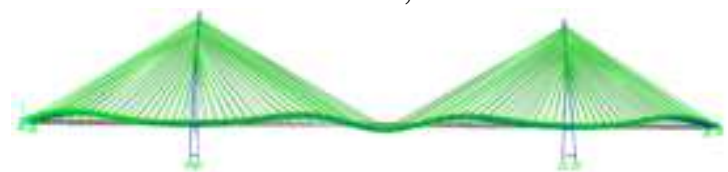

Gambar 15. Mode $12, \mathrm{~T}=0.7930$ detik

\subsection{Respon Displacement}

Displacement akan ditinjau baik dari arah $\mathrm{X}, \mathrm{Y}$, maupun Z. Akan diambil displacement yang terbesar disetiap arah nya untuk dibandingkan dengan displacement yang diijinkan pada jembatan. Batas displacement pada bentang utama jembatan adalah $\Delta \leq \mathrm{L} / 800$ dimana L sebesar 642 meter, maka displacement yang dijinkan tidak lebih dari $80,25 \mathrm{~cm}$.

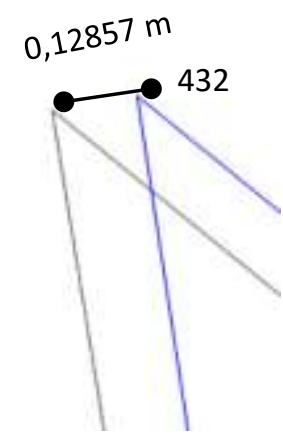

Gambar 16. Joint displacement di titik 432

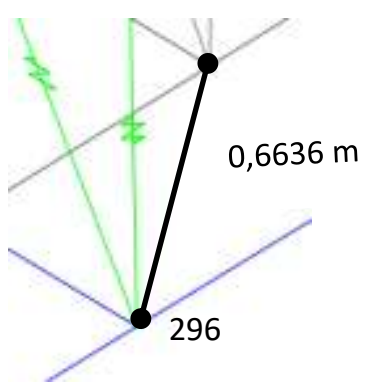

Gambar 17. Joint displacement di titik 296

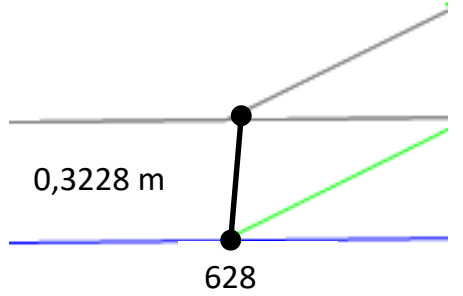

Gambar 18. Joint displacement di titik 628 
Titik 432 merupakan perpindahan terbesar arah $\mathrm{X}$ dengan besar perpindahan akibat adanya beban mati sebesar 0,756215 meter dan akibat adanya beban kombinasi sebesar 0,884791 meter. Perpindahan terbesar arah $\mathrm{Y}$ terdapat pada titik 296 dengan besar perpindahan akibat beban mati adalah -0.00022 meter dan akibat beban kombinasi adalah 0,6658 meter. Dan untuk titik 628 tejadi perpindahan terbesar arah $\mathrm{Z}$ dengan besar perpindahan yaitu $-2,2879$ meter akibat beban mati dan sebesar -2,61073 meter akibat beban kombinasi.

\subsection{Respon Tegangan}

Peneliti menggunakan tegangan pada S11 untuk menganalisis tegangan yang terjadi pada struktur jembatan. Pemilihan tegangan pada S1 1 berdasarkan besarnya tegangan yang paling besar antara S11 yaitu tegangan aksial, S12 yaitu tegangan akibat geser, dan S13 yaitu tegangan akibat lentur. S11 yang akan dibandingkan adalah tegangan terbesar yang terjadi pada setiap penampang struktur jembatan. Tegangan aksial (S11) yang terjadi pada setiap penampang berbeda-beda. Tidak hanya pada besar tegangan yang dihasilkan, namun juga kondisi yang dialami oleh penampang juga berbeda. Jika tegangan bernilai negatif maka penampang tersebut mengalami tekan, dan jika tegangan bernilai positif maka penampang tersebut mengalami tarik.

- Gelagar Melintang

Pada gelagar melintang, S11 maksimal terdapat pada batang 1 yang terbuat dari beton dengan mengalami kondisi tekan. Terjadi peningkatan pada tegangan pada batang 1 akibat gempa sebesar $3233488,28 \mathrm{kgf} / \mathrm{m} 2$.

- Gelagar Induk

S11 terbesar pada gelagar induk beton terdapat pada batang 648. Batang ini mengalami kondisi tarik dengan besar penambahan tegangan akibat gempa 2036584,03 kgf/m2.

- Pylon

Batang 577 merupakan batang beton yang mengalami tegangan maksimal pada pylon. Besar peningkatan tegangan akibat adanya gempa adalah 2517580,04 kgf/m2 dengan batang mengalami tekan.

- Balok Pylon

Batang beton yang mengalami tegangan maksimal pada balok pylon adalah batang 221 . Pada batang ini, terjadi penambahan tegangan akibat adanya gempa sebesar 12460034,4 $\mathrm{kgf} / \mathrm{m} 2$ dengan kondisi tekan.
- Kabel

Pada kabel tegangan maksimal terdapat pada batang 921. Kabel mengalami kondisi tarik dengan penambahan tegangan sebesar $14194360,6 \mathrm{kgf} / \mathrm{m} 2$.

\subsection{Gaya yang Terjadi pada Kabel}

Kabel 921 merupakan kabel yang mempunyai tegangan maksimal dibanding dengan kabel yang lain.

Berdasarkan perusahaan Tensacciai yang memproduksi kabel untuk jembatan cable stayed, gaya maksimum yang mampu ditahan kabel akibat beban kerja adalah $45 \%$ dari gaya tarik putus kabel. Maka, gaya maksimum yang mampu ditahan kabel ( $\varnothing \mathrm{Pn})$ sebesar $21.218 \mathrm{kN}$. Maka , $\mathrm{Pu}=4407650,82 \mathrm{~kg}=44076,508 \mathrm{kN}$ $\emptyset \mathrm{Pn}=21218 \mathrm{kN}$ $\mathrm{Pu} \leq \varnothing \mathrm{Pn}$

$44076,508 \geq 21218$

(kabel tidak kuat menahan beban yang terjadi)

\section{KESIMPULAN \\ 5.1 Kesimpulan}

Setelah dilakukan analisis pada struktur jembatan Tengku Fisabililah terhadap pengaruh gempa Hyogo-Ken Nanbu, didapat kesimpulan sebagai berikut :

1. Terdapat banyak mode shapes yang dihasilkan pada jembatan yang berbedabeda bentuk nya. Mode 1 adalah mode terbesar untuk arah sumbu Y dengan periode 4,9351 detik, mode 9 adalah mode terbesar arah sumbu $\mathrm{X}$ dengan periode 0,9297 detik, dan mode 12 adalah mode terbesar dari arah sumbu $\mathrm{Z}$ dengan periode 0,793 detik. Dari ketiga sumbu ini, mode paling besar terdapat pada sumbu Y jembatan yang menandakan sumbu yang mengalami efek terbesar akibat adanya gempa.

2. Displacement terbesar untuk arah $\mathrm{X}$ terletak pada titik 432 dengan besar displacement $88,4791 \mathrm{~cm}$, terbesar arah Y terletak pada titik 296 sebesar 66,578 $\mathrm{cm}$, sedangkan pada titik 628 terjadi displacement sebesar $-261,073 \mathrm{~cm}$ untuk arah Z. Diketahui displacement yang diijinkan adalah $80,25 \mathrm{~cm}$. Maka untuk arah $\mathrm{X}$ dan $\mathrm{Z}$, displacement yang terjadi melebihi batas displacement ijin.

3. Hasil analisis diperoleh tegangan maksimal yang terjadi pada gelagar melintang sebesar $-4070746,3 \mathrm{kgf} / \mathrm{m} 2$ di batang 1, pada gelagar induk sebesar 
$8544879,8 \mathrm{kgf} / \mathrm{m} 2$ di batang 648, pada pylon sebesar $-7884948,9 \mathrm{kgf} / \mathrm{m} 2 \mathrm{di}$ batang 577, pada balok pylon sebesar $13694024,5 \mathrm{kgf} / \mathrm{m} 2$ di batang 221, dan pada kabel sebesar 134851867,6 kgf/m2 di kabel 921. Dari tegangan maksimum yang terjadi disetiap penampangnya, tegangan pada kabel lah yang mempunyai tegangan paling maksimum. Gaya yang terjadi pada kabel akibat gempa $(44076,508 \mathrm{kN})$ lebih besar dari gaya maksimum yang mampu ditahan kabel $(21218 \mathrm{kN})$.

\subsection{Saran}

Adapun saran untuk analisis ini adalah:

1. Peneliti memerlukan data pemodelan yang asli dan terjamin untuk melakukan pemodelan Jembatan Tengku Fisabililah sehingga pemodelan sama persis seperti kenyataan.

2. Time history dapat diambil dari gempa yang terjadi di Indonesia, mengingat Indonesia juga merupakan negara yang rawan mengalami gempa.

3. Tidak hanya $\operatorname{arah} \mathrm{X}$ dan $\mathrm{Y}$ secara horizontal, data percepatan tanah juga bisa dimasukan arah $\mathrm{Z}$ secara vertikal karna gempa bumi pada kenyataannya terjadi pada semua arah.

\section{DAFTAR PUSTAKA}

[1] Badan Standardisasi Nasional. SNI-1725-2016 Pembebanan untuk Jembatan. Jakarta: Badan Standardisasi Nasional.

[2] Supriadi, Bambang., Agus Setyo Muntohar. Jembatan. Cetakan Ke-4. Yogyakarta: Beta Offset.2007.

[3] Jankar, Yogesh B.; Suresh M. R. Time-History Analysis of A Cable Stayed Bridge for Various Spans and Pylon Height. IRJET. Vol.5. Issue 10. 2018

[4] Dubey, S.K; Prakash Sangamnerkar; Ankit A. G. Dynamic Analysis of Structures Subjected To Earthquake Load. International Journal of Advance Engineering and Research Development. Vol.2. Issue 9. 2015.

[5] Prof. Dr. QaiseruzZaman Khan (2010), "Evaluation Of Effects Of Response Spectrum Analysis On Height Of Building" International Conference on Sustainable Built Environment (ICSBE-2010) Kandy, 13-14 December 2010

[6]. Romy Mohan, C Prabha . Dynamic Analysis of RCC Buildings with Shear Wall. International Journal of Earth Sciences and Engineering ISSN 0974-5904, Volume 04, No 06 SPL, October 2011, pp 659-662.2011 